\title{
Weathered antlers: a valuable source of DNA useful for conservation purposes for Cervids
}

\author{
Claudia Greco*, Anna Maria De Marinis, Francesco Riga, Nadia Mucci
}

Department for the Monitoring and Protection of the Environment and for Biodiversity Conservation, Italian Institute for Environmental Protection and Research ISPRA, Ozzano dell'Emilia, BO, Italy; annamaria.demarinis@isprambiente.it; francesco.riga@isprambiente.it; nadia.mucci@isprambiente.it

* Corresponding author: Claudia Greco, Via Cà Fornacetta 9, I-40064 Ozzano dell’Emilia, BO, Italy; claudia.greco@isprambiente.it

Simple Summary: Deer conservation strategies requests genetic studies. Different biological materials are used as a source of DNA among which antlers represent a promising alternative in genetics studies of deer populations. Antlers are deciduous structures that grow and cast annually, mainly composed of bone tissue, arising from the frontal bone on the head of male deer, except in reindeer. Antlers are easily accessible in private or public collections or museums where are conserved as trophies or historical artefacts. In addition, antlers can be collected in the field without stressing animals, but cast antlers are weathered due to exposure to thermal excursions, solar irradiation, and rains, that enhance the effects of rodent gnawing activity that causes warping, cracking and breakage of antlers. This study confirmed that DNA extraction is possible from weathered antlers also in Mediterranean climate. We obtained good DNA quality and quantity drilling the antler base. DNA non invasive extraction from antlers powder is low cost and short time-consuming laboratory procedure and hence is a useful tool for management purposes and future reintroduction projects of endemic and threatened deer.

\begin{abstract}
Increasingly, conservation genetics pinpoint the use of biological matrices collected without stressing wildlife. Cervid's antlers seem to fit with this need. We verified the amplification success rate from DNA obtained from red deer antlers collected in the State Nature Reserve of Bosco della Mesola, Northern Italy and its use for conservation purposes. Here occurs the only native red deer population of peninsular Italy, recently recognized as a distinct subspecies (Cervus elaphus italicus). Four antlers stored at room temperature for four years and four samples highly degraded by environmental conditions were analyzed using a multimarker approach. We utilized a simple, inexpensive method to extract DNA from drilled antlers powder. This study confirms that weathered antlers can be a suitable source of DNA also in Mediterranean climates and pointed out that burr drilling yielded good quality amplifiable DNA. Antlers can be used in particular for molecular genetic studies on rare or threatened species of cervids as providing non-invasive sampling.
\end{abstract}

Keywords: Cervus elaphus italicus, antlers, mitochondrial DNA (mtDNA), Growth Hormone, loci microsatellite (STR) 


\section{Introduction}

Genetics has assumed an increasingly important role in the management and conservation of wildlife ${ }^{1-2}$ and in particular of cervid populations ${ }^{3}$. Different biological material can be used as a source of DNA such as blood, hairs and faeces. The invasive sampling of blood and hairs may lead captured deer to high stress levels and trauma, even up to a sudden death, which is a major concern when dealing with sensitive and threatened species ${ }^{4-6}$. Faeces are difficult to find and provide a low amount of degraded DNA. Antlers represent a promising alternative approach in genetics studies of deer populations because they can be collected in the field without stressing the animals. Moreover, they are easily accessible even in high numbers in the private or public collections or museums where they are conserved as trophies or historical artefacts. Antlers stored under controlled conditions permit studying population genetics over time 7 , also comparing extant, historical and fossil specimens ${ }^{8-10}$.

Deer males shed antlers once a year and tissues are desiccated before the antlers fall off protecting the DNA. A collection can be created to meet specific research objectives.

Cast antlers can be weathered due to exposure to abiotic agents as temperature, solar irradiation, rains, etc. These agents enhance the negative effects of biotic factors as rodent gnawing activity that causes warping, cracking and breakage of antlers. Lopez and Beier ${ }^{11}$ observed that antlers of white-tailed deer (Odocoileus virginianus) and mule deer (Odocoileus hemionus) that have been exposed to weathering in a semi-desert environment for 1-7 years yielded amplifiable DNA while for over 8 years failed to produce reliable DNA. Antler drilling allows collecting the small amount of powder necessary to DNA extraction. Antlers weathered in the field were drilled into the base where they attach to pedicle bone (Lopez and Beier ${ }^{11}$. Trophies were drilled on the backside of the antler so they were not damaged and the borehole was on the far side (Hoffmann and Griebeler ${ }^{12}$. In these laboratory protocols, it is not reported if the quantity of DNA found in antlers depends on drilling position.

Both well preserved antlers housed in a collection and weathered antlers were tested as a source of DNA for the population of the Mesola red deer (Cervus elaphus italicus), the only native red deer of peninsular Italy, recently recognized as a distinct subspecies ${ }^{13}$. This population inhabits the State Natural Reserve "Bosco della Mesola" (Ferrara province, Northern Italy) and became nearly extinct in the $20^{\text {th }}$ Century; nowadays this small population has slightly recovered and its total number is at least 300 heads. We evaluated the DNA extracted from both the beam (only for weathered materials) and the burr of antlers analysing the most common markers (mitochondrial DNA and loci microsatellite) in addition to a short region of the gene encoding for the Growth Hormone $(\mathrm{GH})$. The aims of this study are threefold: 1. confirm that DNA extraction is possible from weathered antlers as well as from trophy collections has already reported in previous studies; 2 . find which drilling position on burr and beam allows obtaining the higher DNA quality and quantity. 3. verify that the Mediterranean climates of the study area do not affect the DNA quality.

\section{Materials and methods}

A total of eight antlers was collected inside the State Natural Reserve. Four antlers in perfect conditions were collected in 2014 from rangers and housed at room temperature in a warehouse, they differ in size and presented from two to four tines; the mean number of tines/antler pair is much lower in Mesola stags than in other European populations of red deer (Mattioli and Ferretti 2014). The remaining four antlers were exposed in the field to different environmental conditions for years and remains of broken and worn antlers were collected in 2018. The burr of each antler, held steady in a vice, was pulverized in a single hole to a depth of around $8 \mathrm{~mm}$ with a Dremel precision drill with a $3 \mathrm{~mm}$ diamond engraving drill bit. The small amount of powder produced was collected on a clean sheet of tinfoil for each sample and then transferred to $2 \mathrm{ml}$ empty safe-lock sterile tube. The drill bit was flame-sterilized after each drilling. Additionally, also the beams of the four weathered samples were drilled to compare the results (Figure 1).

DNA was extracted from powdered antlers using DNeasy Blood and Tissue Kit (Qiagen) on the robotic workstation QIAcube extractor. Three different types of molecular markers were amplified to test the efficiency in studies concerning phylogenetic analysis, population structure, and a gene associated featuring. We choose to amplify a short region of the gene encoding Growth Hormone (GH), intron 1, in both burr and beam of each sample to verify any difference between the two sample matrices ${ }^{14-15}$.

We analyzed also the starting region of the mtDNA control region ${ }^{16}$, a panel of twelve microsatellite loci STR 17-23, and Growth Hormone GH nuclear gene ${ }^{14-15}$. Primer utilized and bibliographic references are listed in Table 1. PCRs were carried out in $8 \mu \mathrm{l}$ of total volume using the following protocol $2 \mu \mathrm{l}$ DNA, $0.04 \mu \mathrm{l}$ Hotstart Taq, $0.20 \mu \mathrm{l}$ Primer (forward and reverse), and $0.4 \mu \mathrm{l}$ DNTPs. Amplicons of the control region and GH gene 
were purified with Exonuclease I and Phosphatase and sequenced with Big Dye terminator chemistry (Thermo Fisher Scientific) following the manufacturer protocol in a $10 \mu \mathrm{l}$ of final volume. Sequences and STRs fragments were separated on an ABI prism 3500 Genetic Analyzer (Thermo Fisher Scientific) and corrected respectively with the software Seqscape 3.0 and GeneMapper 5.0. (Thermo Fisher Scientific) then DNAsp ${ }^{24}$ was used to compute haplotype diversity for sequence analysis while GeneAlEx $6.05{ }^{25}$ was utilized to calculate variability indices (observed and expected heterozygosity, allele number, percentage of polymorphic loci).

\section{Results}

A sequence around $600 \mathrm{bp}$ long was obtained for the GH gene for all the antlers. The specimens shared the same unique haplotype, corresponding to the variant B haplotype found in cervids (Genebank Acc. N. AM049993.1). Both shed and weathered antlers gave reliable data from burr extraction. On the contrary, DNA extracted from the beam of weathered antlers, gave poor amplification results, therefore was excluded from the following analyses. The amplification of the short mtDNA region produced an alignment of around 200 bp for 7 individuals out of 8 tested. Samples shared an identical haplotype corresponding to AF291887.1 of Genebank (Cervus elaphus italicus).

The analysis of STRs led to a PCR success value equal to 93.3\%. All the STRs but one resulted polymorphic (92.3\%). The low number of samples did not allow running statistical analyses.

Despite the fence presence has hampered the gene flow with other deer populations, we recorded discrete levels of genetic variability. Mean number of alleles was equal to $3.007 \pm 0.265$, and values of observed and expected heterozygosity were respectively $0.351 \pm 0.053$ and $0.433 \pm 0.052$. Departure from Hardy Weinberg Equilibrium (HWE) was slightly significant, probably due to the low number of samples collected $(\mathrm{p}<0.05)$. Low PID values were recorded ( $\mathrm{PID}=1,0 \times 10^{-6}$; PID SIB $=1.9 \times 10^{-9}$ ). All the eight multilocus genotypes showed a different allelic composition. No less than three mismatches were found between genotypes, thus supporting the assignment of antlers to eight different males.

\section{Discussion}

Our results confirm that antlers can be considered a valuable source of DNA even if they are weathered for years and deteriorated from biotic and abiotic agents. An easy sampling procedure (antler field collection) just a simple DNA extraction protocol, only a few grams of pulverized antler, without any specific treatment, makes this methodology effective, easy to use and inexpensive. Regarding the drilling position to gain material for DNA extraction, we agree with ${ }^{12}$ that the hole should be located on the backside of the base of the beam and the far side of a wall-mounted trophy. In the case of weathered antlers, we suggest drilling the burr in the middle, at the junction of burr and pedicle. Our results highlighted that only the burr yielded amplifiable DNA from all the samples, regardless of the level of weathering and degradation, obtaining nuclear and mitochondrial DNA sequences as well as the genotypization of a panel of 12 microsatellite loci. High genotyping and sequencing success rate suggest that this material is less affected by biotic and abiotic factors than organic traces left from animals on the ground (hairs, urine, scats, etc.). Although the small number of samples and the possibility of inbreeding in a small and isolated population, the 12 STRs were enough polymorphic to obtain a unique multilocus genotype for each individual, no matching was found, consequently, the method could be useful for population genetic studies. Our results confirm what has been achieved in previous studies with antlers old from several (Lopez and Beier ${ }^{11}$ up to 200 years ${ }^{12}$. As weathering rates do not affect the possibility to utilize this source of DNA, also ancient antlers or antler artefacts can be a good starting material for genetic studies. Antler artefacts allow knowing human societies of the past, for example by the reconstruction of ancient trade routes ${ }^{26-27}$. Indeed, medieval craftspeople's artefacts and manufacture's wasting products ${ }^{28}$ obtained from reindeer antlers provided good quality DNA. Besides, we have shown that marked Mediterranean seasonality of the study area characterized by cold and humid winter followed by hot and dry summer does not affect the amplifiability of weathered antlers DNA samples.

Despite these results can be available only for males, the easy extraction method combined with the variety of different markers contribute to making antlers a valuable tool for species identification, intra and inter population variability, phylogenesis, demography and functional genes, individual genotyping and kinship studies. 


\section{Conclusions}

Antlers analysis offers a good chance to obtain information avoiding capture and possible death and allows a wide non-invasive genetic sampling for comparative studies. In particular, for continuous monitoring of Mesola red deer, this approach would be recommended to avoid any disturbance to the relict population. Antlers revealed a useful tool for the evaluation of genetic variability of the endangered Mesola red deer for management purposes and future reintroduction projects outlined in the action plan ${ }^{29-30}$.

Author Contributions: Conceptualization, N.M. and C.G.; Methodology, C.G.; Software, N.M.; Validation, C.G., A.M.D.M. and N.M.; Formal Analysis, C.G.; Investigation, A.M.D.M.; Resources, F.R.; Data Curation, A.M.D.M.; Writing - Original Draft Preparation, C.G.; Writing - Review \& Editing, A.M.D.M.; Visualization, F.R.; Supervision, N.M..

Funding: This research received no external funding.

Institutional Review Board Statement: Not applicable.

Data Availability Statement: The data presented on this study are available on request from the corresponding author.

Acknowledgments: We wish to thank all the staff of the State Natural Reserve "Bosco della Mesola".

Conflicts of Interest: The authors declare no conflict of interest.

\section{References}

1. Arif, I. A.; Khan, H. A.; Bahkali, A. H.; Al Homaidan, A. A.; Al Farhan, A. H.; Al Sadoon, M.; Shobrak, M., DNA marker technology for wildlife conservation. Saudi Journal of Biological Sciences 2011, 18 (3), 219-225.

2. Holderegger, R.; Balkenhol, N.; Bolliger, J.; Engler, J. O.; Gugerli, F.; Hochkirch, A.; Nowak, C.; Segelbacher, G.; Widmer, A.; Zachos, F. E., Conservation genetics: Linking science with practice. Molecular Ecology 2019, 28 (17), 3848-3856.

3. Schwartz, M. K.; Luikart, G.; Waples, R. S., Genetic monitoring as a promising tool for conservation and management. Trends in Ecology and Evolution 2007, 22 (1), 25-33.

4. DeNicola, A. J.; Swihart, R. K., Capture-induced stress in white-tailed deer. Wildlife Society bulletin 1997, 25 (2), 500-503.

5. Powell, R. A.; Proulx, G., Trapping and Marking Terrestrial Mammals for Research: Integrating Ethics, Performance Criteria, Techniques, and Common Sense. ILAR Journal 2003, 44 (4), 259-276.

6. Huber, C. D.; Kim, B. Y.; Marsden, C. D.; Lohmueller, K. E., Determining the factors driving selective effects of new nonsynonymous mutations. Proceedings of the National Academy of Sciences 2017, 114 (17), 4465-4470.

7. Wandeler, P.; Hoeck, P. E.; Keller, L. F., Back to the future: museum specimens in population genetics. Trends Ecol Evol 2007, 22 (12), 634-42.

8. Meiri, M.; Kosintsev, P.; Conroy, K.; Meiri, S.; Barnes, I.; Lister, A., Subspecies dynamics in space and time: A study of the red deer complex using ancient and modern DNA and morphology. Journal of Biogeography 2018, 45 (2), 367-380.

9. Schnitzler, A.; Granado, J.; Putelat, O.; Arbogast, R.-M.; Drucker, D.; Eberhard, A.; Schmutz, A.; Klaefiger, Y.; Lang, G.; Salzburger, W.; Schibler, J.; Schlumbaum, A.; Bocherens, H., Genetic 
diversity, genetic structure and diet of ancient and contemporary red deer (Cervus elaphus L.) from north-eastern France. PLOS ONE 2018, 13 (1), e0189278.

10. Kang, M. C.; Han, S. H.; Jung, Y. H.; Oh, J. H.; Kim, G. O.; Ko, J. W.; Oh, M. Y., Genetic analysis of ancient bones of Cervidae animals from archaeological site in Jeju, Korea. Integrative Biosciences 2007, 11 (2), 147-153.

11. Lopez, R. G.; Beier, P., Weathered antlers as a source of DNA. Wildlife Society Bulletin 2012, 36 (2), 380-382.

12. Hoffmann, G. S.; Griebeler, E. M., An improved high yield method to obtain microsatellite genotypes from red deer antlers up to 200 years old. Molecular Ecology Resources 2013, 13 (3), 440446.

13. Zachos, F. E.; Mattioli, S.; Ferretti, F.; Lorenzini, R., The unique Mesola red deer of Italy: taxonomic recognition (Cervus elaphus italicus nova ssp., Cervidae) would endorse conservation\#. Italian Journal of Zoology 2014, 81 (1), 136-143.

14. Lioupis, A.; Wallis, O. C.; Wallis, M., Cloning and characterisation of the gene encoding red deer (Cervus elaphus) growth hormone: implications for the molecular evolution of growth hormone in artiodactyls. J Mol Endocrinol 1997, 19 (3), 259-66.

15. Wallis, O. C.; Bill, L. J.; Burt, E. J.; Ellis, S. A.; Wallis, M., Polymorphism of the growth hormone gene of red deer (Cervus elaphus). General and comparative endocrinology 2006, 146 (2), 180185.

16. Randi, E.; Pierpaoli, M.; Danilkin, A., Mitochondrial DNA polymorphism in populations of Siberian and European roe deer. Heredity 1998, 80 (4), 429-437.

17. Bishop, M. D.; Kappes, S. M.; Keele, J. W.; Stone, R. T.; Sunden, S. L.; Hawkins, G. A.; Toldo, S. S.; Fries, R.; Grosz, M. D.; Yoo, J.; et al., A genetic linkage map for cattle. Genetics 1994, 136 (2), 619-39.

18. Kemp, S. J.; Hishida, O.; Wambugu, J.; Rink, A.; Teale, A. J.; Longeri, M. L.; Ma, R. Z.; Da, Y.; Lewin, H. A.; Barendse, W.; Teale, A. J., A panel of polymorphic bovine, ovine and caprine microsatellite markers. Animal Genetics 1995, 26 (5), 299-306.

19. Røed, K. H.; Midthjell, L., Microsatellites in reindeer, Rangifer tarandus, and their use in other cervids. Molecular Ecology 1998, 7 (12), 1773-1776.

20. Talbot, S. L.; Shields, G., A phylogeny of the Bears (Ursidae) inferred from complete sequence of three mitochondrial genes. Molecular Phylogenetics and Evolution 1996, 5 (3), 567-575.

21. Penty, J. M.; Henry, H. M.; Ede, A. J.; Crawford, A. M., Ovine microsatellites at the OarAE16, OarAE54, OarAE57, OarAE119 and OarAE129 loci. Anim Genet 1993, 24 (3), 219.

22. Ede, A. J.; Pierson, C. A.; Crawford, A. M., Ovine microsatellites at the OarCP9, OarCP16, OarCP20, OarCP21, OarCP23 and OarCP26 loci. Anim Genet 1995, 26 (2), 129-30.

23. Barendse, W.; Armitage, S. M.; Kossarek, L. M.; Shalom, A.; Kirkpatrick, B. W.; Ryan, A. M.; Clayton, D.; Li, L.; Neibergs, H. L.; Zhang, N.; Grosse, W. M.; Weiss, J.; Creighton, P.; McCarthy, F.; Ron, M.; Teale, A. J.; Fries, R.; McGraw, R. A.; Moore, S. S.; Georges, M.; Soller, M.; Womack, J. E.; Hetzel, D. J. S., A genetic linkage map of the bovine genome. Nature Genetics 1994, 6 (3), 227-235.

24. Librado, P.; Rozas, J., DnaSP v5: A software for comprehensive analysis of DNA polymorphism data. Bioinformatics 2009, 25 (11), 1451-1452.

25. Peakall, R.; Smouse, P. E., GenAlEx 6.5: genetic analysis in Excel. Population genetic software for teaching and research - an update. Bioinformatics 2012, 28 (19), 2537-2539.

26. Stanton, D. W. G.; Mulville, J. A.; Bruford, M. W., Colonization of the Scottish islands via long-distance Neolithic transport of red deer $(<\mathrm{i}>$ Cervus elaphus $</ \mathrm{i}>)$. Proceedings of the Royal Society B: Biological Sciences 2016, 283 (1828), 20160095.

27. Rosvold, J.; Hansen, G.; Røed, K., From mountains to towns: DNA from ancient reindeer antlers as proxy for domestic procurement networks in medieval Norway. Journal of Archaeological Science: Reports 2019, 26, 101860. 
28. Røed, K.; Hansen, G., DNA from Ancient Reindeer Antler as Marker for Transport Routes and Movement of Craftspeople, Raw Material and Products in Medieval Scandinavia. In Indrelid S, Hjelle KL, Stene K, Berglund B, Callanan ME, Kaland SHH, Stenvik LF. Exploitation of outfield resources Joint Research at the University Museums of Norway, University Museum, University of Bergen: 2015; pp p. 69-74.

29. Mattioli, S.; Fico, R.; Lorenzini, R.; Nobili, G., Mesola red deer: physical characteristics, population dynamics and conservation perspectives. Hystrix, the Italian Journal of Mammalogy 2003, $14(1-2)$.

30. Lovari, S.; Nobili, G., Programma nazionale di conservazione del cervodella Mesola. . Ministero dell'Ambiente e della Tutela del Terri-torio e del Mare, Ministero delle Politiche Agricole Alimentari e Forestali ; Corpo Fore-stale dello Stato; I.S.P.R.A.: 2010 Vol. n. 36.

Figure 1. Drilling procedure of antler Mesola red deer A. Antler housed in storehouse, held in a vice; the burr is pulverized in a single hole in the middle of the antler base. B. Weathered antler; the beam is pulverized in a single hole to $2 \mathrm{~cm}$ from the burr.

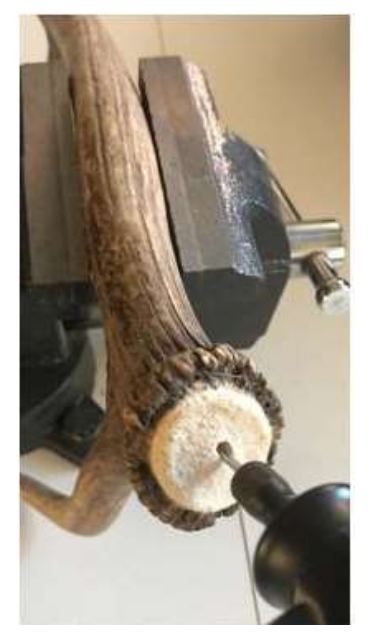

(a)

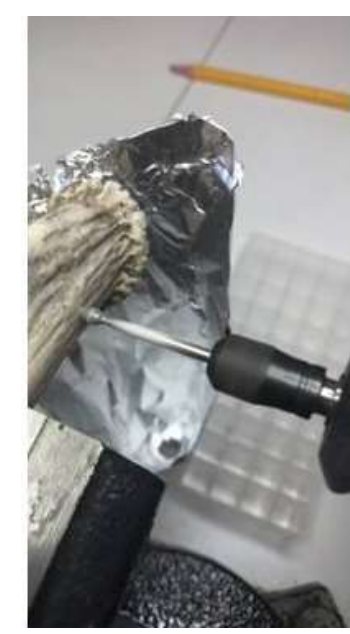

(b)

Table 1. Complete primer list and bibliographic references.

\begin{tabular}{ccc}
\hline Marker & Type & Reference \\
\hline BM1258 & STR & Bishop et al., 1994 \\
\hline BM203 & STR & Talbot et al., 1996 \\
\hline BM4107 & STR & Talbot et al., 1996 \\
\hline BM5004 & STR & Talbot et al., 1996 \\
\hline ILSTS008 & STR & Kemp et al., 1995 \\
\hline NVHRT16 & STR & Roed and Midthjell, 1998 \\
\hline NVHRT48 & STR & Roed and Midthjell, 1998 \\
\hline NVHRT73 & STR & Roed and Midthjell, 1998 \\
\hline OARAE129 & STR & Penty et al., 1993 \\
\hline OARFCP26 & STR & Ede et al., 1995 \\
\hline OARFCB304 & STR & Talbot et al., 1996 \\
\hline TGLA53 & STR & FAO, 2004 \\
\hline
\end{tabular}




\begin{tabular}{ccc} 
LCAPPRO & SEQ & Douzery and Randi, 1997 \\
GH & SEQ & Lioupis and Wallis, 1997 \\
\hline
\end{tabular}

